\title{
A method for the complete analysis of NORM building materials by $\gamma$-ray spectrometry using HPGe detectors
}

\author{
B. Quintana ${ }^{a}, *$ M.C. Pedrosa ${ }^{a}$, L. Vázquez-Canelas ${ }^{a}$, R. Santamaría ${ }^{a}$, M.A. Sanjuán ${ }^{b}, F$. Puertas $^{\mathrm{c}}$ \\ a Laboratorio de Radiaciones Ionizantes, Departamento de Física Fundamental, Universidad de Salamanca, Spain \\ b Instituto Español del Cemento y sus Aplicaciones, IECA, Spain \\ ${ }^{c}$ Instituto de Ciencias de la Construcción Eduardo Torroja, CSIC, Spain
}

\section{A R T I C L E I N F O}

\section{Keywords:}

Low-level background $\gamma$-ray spectrometry

Broad energy Ge detectors

NORM building materials

$\gamma$-ray spectrum analysis, Monte Carlo simulated

efficiencies

True-coincidence-summing corrections

\begin{abstract}
A B S T R A C T
A methodology including software tools for analysing NORM building materials and residues by low-level gamma-ray spectrometry has been developed. It comprises deconvolution of gamma-ray spectra using the software GALEA with focus on the natural radionuclides and Monte Carlo simulations for efficiency and true coincidence summing corrections. The methodology has been tested on a range of building materials and validated against reference materials.
\end{abstract}

\section{Introduction}

The use of residues containing enhanced activities of natural radionuclides (NORM) in the manufacturing of materials for the construction industry has become increasingly challenging, as this procedure contributes to reduce the natural resources needed to fabricate the building materials. The COST Action TU1301, "NORM for building materials (NORM4Building)", aims to encourage collaboration among scientists, industries and regulators to stimulate research regarding this issue, and to assess the impact of external gamma exposure on populations and indoor air quality. The objectives of this action include the evaluation and development of specific measurement procedures that can be easily adopted by laboratories to estimate the radiological impact of NORM materials and to support the standardization of these procedures.

According to the European Council Directive (2013)/59/Euratom (2013), the level of indoor external exposure to gamma radiation emitted by building materials should be less than $1 \mathrm{mSv} \mathrm{y}^{-1}$. In addition, the directive proposed the Activity Concentration Index (ACI) as a conservative screening tool for identifying building materials that may exceed this level. The ACI is calculated as follows:

$A C I=\frac{C_{226} R a}{300}+\frac{C_{232} T h}{200}+\frac{C_{40}}{3000}$,

where $C_{226_{R a}}, C_{232} \mathrm{Th}$ and $C_{40}$ are the activity concentrations in $\mathrm{Bq} / \mathrm{kg}$ for ${ }^{226} \mathrm{Ra}$ (equivalent to ${ }^{238} \mathrm{U}$ and ${ }^{234} \mathrm{U}$ in secular equilibrium conditions), ${ }^{232} \mathrm{Th}$ and ${ }^{40} \mathrm{~K}$, respectively. Additionally, the calculation of dose must take into account other factors such as density, material thickness, as well the type of building material and the intended use. However, in order to calculate the ACI, practical methods capable of measuring ${ }^{226} \mathrm{Ra},{ }^{232} \mathrm{Th}$ (or its decay product ${ }^{228} \mathrm{Ra}$ ) and ${ }^{40} \mathrm{~K}$ are still required.

Gamma spectrometry is a suitable technique to measure these types of radionuclides because it can simultaneously detect all of the gamma emitters contained within a given sample. This includes ${ }^{40} \mathrm{~K}$ and all the gamma emitters present in the ${ }^{238} \mathrm{U},{ }^{232} \mathrm{Th}$ and ${ }^{235} \mathrm{U}$ decay chains, providing a more complete radiological characterization of the material being measured.

Once a gamma spectrometry system appropriate for these kinds of environmental measurements was available, two main issues were taken into account: determining measurement efficiency and the computational analysis of the gamma spectrum. In the present study, the Monte Carlo calculation using Geant4, a tool that allows for implementation of measurement geometries and matrix characteristics, was used to determine the efficiency calibration of each material and geometry. This method is suitable for the analysis of building materials because it provides efficiencies for any type of geometry and matrix with a minimum of working hours and without bearing long times of measurement. Coincidence summing corrections were also estimated for some emissions by means of the Monte Carlo simulations. However, regarding spectrum analysis, the main difficulty involved the characteristics of the spectra of the natural decay series, where the main peaks were found in the low energy range on a high-level continuum background. Galea (Santamaría et al., 2017), the spectrum analysis tool used in this work, implements a genetic algorithm-based peak fitting

\footnotetext{
* Corresponding author.

E-mail address: quintana@usal.es (B. Quintana).
} 
and includes COSPAJ for the spectral continuum estimation (Quintana and Fernández, 1998). Galea provides reliable results of the radionuclide activity present in the material being measured, even with low counting statistics in the full-energy peaks. The main issues associated with the spectral analysis of natural radionuclides were also addressed in this work.

\section{Method}

\subsection{Galea}

The $\gamma$-ray analysis program GAmma Line Expert Analyser (Galea), developed in our laboratory, performs the basic tasks required to analyse any spectrum: the identification of radionuclide emissions and the calculation of the activities corresponding to the emitters. It is made up two main parts. Starting with the raw spectra, the analysis tool locates full-energy peaks and determines the intervals between them. Also, it is essential to accurately estimate the continuum background under the peaks, which is accomplished by the COSPAJ algorithm (Quintana and Fernández, 1998).

Galea also includes a genetic algorithm (GA) for peak analysis that works with the net spectrum generated from the previous step. The algorithm works independently of the number of emissions included in a peak. The fitting algorithm accommodates to the characteristics of the spectra being analysed by using a specific user library with the more likely emissions occurring within the spectra; for example, from natural radionuclides. In building the user library, the emissions data was selected from a reliable radionuclide library. As regards Nucléide-LARA (LNHB, 2017) was chosen, since this source provides a complete compilation of the radionuclide emissions originating from natural decay series. First, the emissions present in the spectrum were identified by associating each peak interval with the emissions included in the user library. The steps generated using the algorithm are shown in the flow chart in Fig. 1. A brief description of the peak-fitting algorithm is provided below, but further details can be found in Santamaría et al. (2017).

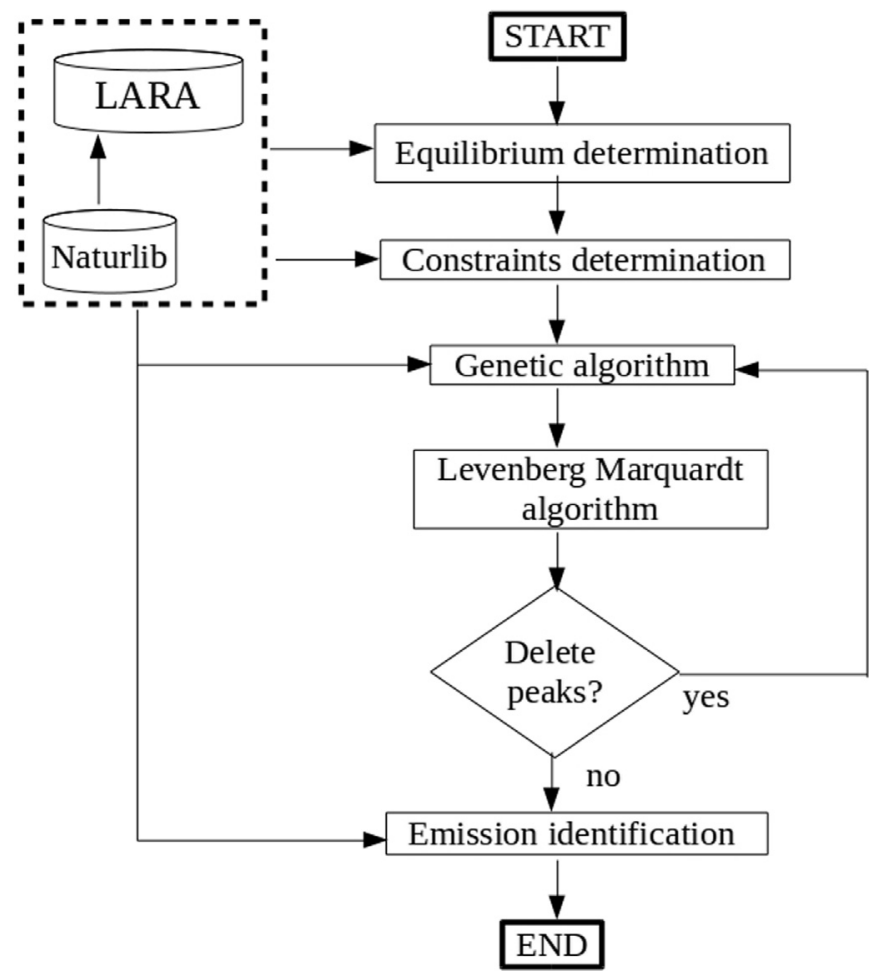

Fig. 1. Flow chart of the peak analysis algorithm.
The peak shape function selected to fit the full-energy peaks measured by the HPGe detectors is given simply by an exponential convoluted with a Gaussian function (Siegert and Janssen, 1990). In the first step, peaks placed within a given interval are fitted by the GA, and then, refined using the Levenberg-Marquardt method. After fitting, the statistical relevance of the fitted peaks over the continuum background is evaluated, and if the test is negative and refitting is required, the peaks are deleted. The statistical relevance of each fitted peak is determined by the decision limit $L_{c}$ (Currie, 1968), calculated for $95 \%$ probability. The last step of the algorithm identifies the emissions present in the spectrum.

Several constraints to the fitting parameter values are needed in order to guarantee the success of the spectrum analysis when counting statistics in the peaks are low. The width parameters of the peak fitting function for shaping the full energy peaks are taken as constant along the fitting intervals. This provides the number of peak shape parameters to fit when peaks are overlapping in a multiplet to keep down and guarantee that the shape parameter values remain similar for all the peaks within the interval, independently of their statistics. Secular equilibrium, once checked with the main emissions of the involved radionuclides, is also used to initialise the peak areas. Reference emissions of all the radionuclides of a natural decay series are compared to determine equilibrium between radionuclides. If the activity computed for the reference emission of a radionuclide and its daughter are statistically equal according to the Student's test, they are considered to be in secular equilibrium. Isotopic relations are also taken into account when the spectrum comes from the natural disintegration series.

\subsection{MC estimation of efficiency and true-coincidence-summing corrections}

Estimation of peak efficiencies was carried out by Monte Carlo simulations with the Geant4 toolkit (Agostinelli et al., 2003), at the energies of interest for the matrices under study and for each specific measurement condition. The simulation program follows particles and photons emitted from the source to build the history of their energy deposits in the detector, taking into account all the secondary particles and photons generated along their paths. Therefore, it was necessary that quantitative values to implement the matrix characteristics, i.e., atomic composition, density and geometry, were available. For detector characterization, an $\mathrm{X}$ ray was taken to accurately determine its true inner geometry. The deadlayer characterization was performed with SALSA (Hernández-Prieto et al., 2016). The detector geometry implemented is shown in Fig. 2, where the HPGe crystal is outlined in blue and its deadlayer in red. Three interactions processes were considered for photons: photoelectric effect, Compton scattering and pair production. For the electrons generated in such processes, multiple scattering, ionization and bremsstrahlung were taken into account. All these processes are included in the Geant4 Low Energy EM Physics package. The Geant4 9.5 version also allowed the radioactive decay of 2245 isotopes to be simulated, which is particularly interesting to obtain true-coincidence-summing corrections from the simulations (Quintana and Montes, 2014).

Once the experimental geometry was implemented in Geant4, spectra were generated with $10^{6}$ photon events at the energies of interest to evaluate the peak efficiency. This number of events guarantees statistical uncertainties less than $2 \%$ in the efficiency data obtained. To build the simulated spectrum with true-coincidence-summing effects, first the spectrum containing true-coincidence summing effects for the radionuclide of interest was generated. The algorithm implemented in the main program adds all the energy deposits coming from the same disintegration that have been produced in a time period of $1 \mathrm{~ms}$. Secondly, spectra corresponding to mono-energetic sources emitting photons at the same energies as the radionuclide of interest were also generated. Then, the simulated true-coincidence-summing corrections $\left(\mathrm{TCSC}_{\text {sim }}\right)$, associated with the emissions of a given radionuclide, were 


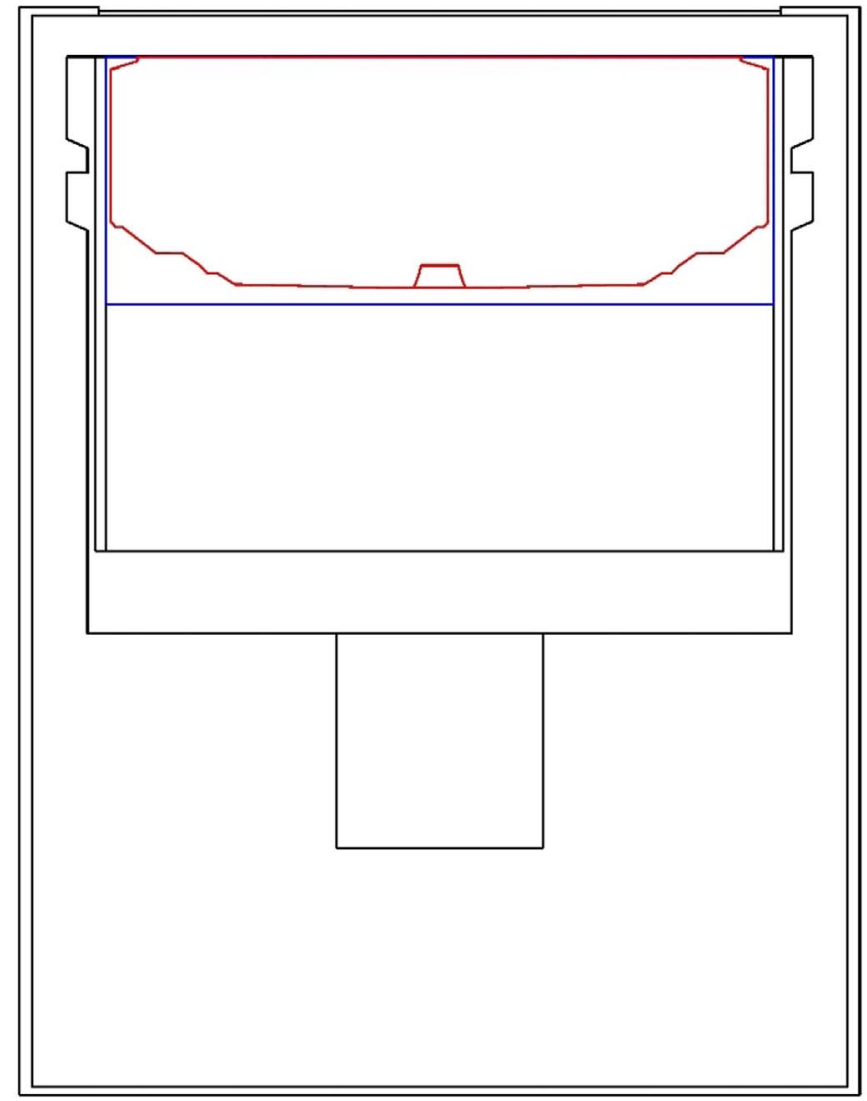

Fig. 2. Outline of the detector geometry, where the HPGe crystal is depicted in blue and its dead layer in red. (For interpretation of the references to color in this figure legend, the reader is referred to the web version of this article.)

calculated as the ratio between the full-energy peak areas at energies $\mathrm{E}_{\gamma}$ obtained for the mono-energetic sources, weighted by the corresponding emission intensities of the radionuclide of interest at the corresponding $\mathrm{E}_{\gamma}$, and the photo-peak areas obtained when the complete radionuclide disintegration was simulated.

The uncertainty budget of the Monte Carlo simulations performed is estimated taking into account the uncertainty associated to the detector geometry and the matrix composition, both obtained by ancillary methods as mentioned above. Regarding detector geometry, the parameters considered are specifically window-to-crystal distance and those related to the implementation of the active volume.

\section{Materials}

The gamma spectrometer used in the measurements and implemented in the Geant4 simulation was a Canberra BEGe detector with an active volume of $117 \mathrm{~cm}^{3}$. The nominal specifications were relative full energy peak efficiency at $1332 \mathrm{keV}$ of $50 \%$ and nominal energy resolution at $122 \mathrm{keV}$ and $1332 \mathrm{keV}$ of $0.75 \mathrm{keV}$ and $2.20 \mathrm{keV}$, respectively. Associated electronics consisted of an integrated module CANBERRA DSA1000 model including a $16 \mathrm{~K}$ multichannel analyser. The detector was shielded with $10 \mathrm{~cm}$ of low-level iron and $5 \mathrm{~cm}$ of old lead, dating from the Eighteenth Century, which was internally lined with $2 \mathrm{~mm}$ thick electrolytic $\mathrm{Cu}$. The detector background peak count rates of interest for the NORM samples are $134(28) \cdot 10^{-6} \mathrm{~s}^{-1}$ at $46.54 \mathrm{keV}$ for ${ }^{210} \mathrm{~Pb}, 102(39) \cdot 10^{-6} \mathrm{~s}^{-1}$ at $186 \mathrm{keV}$ for ${ }^{226} \mathrm{Ra}$, $257(27) \cdot 10^{-6} \mathrm{~s}^{-1}$ at $351.93 \mathrm{keV}$ for ${ }^{214} \mathrm{~Pb}, 186(21) \cdot 10^{-6} \mathrm{~s}^{-1}$ at $609.31 \mathrm{keV}$ for ${ }^{214} \mathrm{~Pb}$ and $910(26) \cdot 10^{-6} \mathrm{~s}^{-1}$ at $1460.82 \mathrm{keV}$ for ${ }^{40} \mathrm{~K}$. There are no traces in the detector background of ${ }^{234} \mathrm{Th}$ or ${ }^{228} \mathrm{Ac}$, daughters of ${ }^{238} \mathrm{U}$ and ${ }^{228} \mathrm{Ra}$, respectively.

The samples analysed are all used as building materials or as additives in the manufacturing of building materials. They included the ceramic tiles used in the intercomparison among laboratories involved in COST action-TU1301 "NORM4Building" (Xhixha et al., 2017), the coal bottom and fly ashes used as mixes in Portland cement, slags also used as mixes, and several types of cement, according to the European Standard EN 197-1:2011: CEM I 42.5 R and CEM I 52.5 R-SR 3. The samples were labelled as CER, for the ceramic sample, BOA, for the bottom ash sample, FA1 and FA2, for the two fly ash samples, SL1 and SL2, for the slag samples, CE1 for the CEM I 42.5 R cement manufactured without NORM mixes and CE2 for the CEM I 52.5 R-SR 3 cement manufactured with FA2 as an additive. All samples were milled and homogenized. Additionally, a compacted cement shaped as a cube was also analysed, which was called CUBE.

Two volumetric geometries were selected to prepare the milled samples for being measured. The first volumetric geometry, labelled as C11, was a polystyrene cylindrical box with a diameter of $42 \mathrm{~mm}$ and a height of $24 \mathrm{~mm}$. The second container, labelled as C21, was a polystyrene cylindrical box with a diameter of $94 \mathrm{~mm}$ and a height of $32 \mathrm{~mm}$. The boxes were filled to different heights depending on the amount of sample available. Samples heights within each box and their bulk densities are given in Table 1 . The polystyrene boxes were not fully protective against radon emanation. Therefore, the gas could flow out depending on the characteristics of the matrix and the amount of space left remaining in the box free from material. The heights of the free inner space in the C21 geometry ranged from $11.4 \mathrm{~mm}$ for CE2 and SL2 up to $12.8 \mathrm{~mm}$ for CER and SL1. The rest of heights were $11.7 \mathrm{~mm}$ for CE1, $12.3 \mathrm{~mm}$ for BOA and $12.4 \mathrm{~mm}$ for FA2. The inner height of the free space for FA1, which was prepared using the C11 geometry, was $5.6 \mathrm{~mm}$. Regarding the compacted cement sample referred to as CUBE, its density was $1.964 \mathrm{~g} / \mathrm{cm}^{3}$ and the lengths of the sides of the samples were $50.65 \mathrm{~mm}, 51.00 \mathrm{~mm}$ and $50.70 \mathrm{~mm}$ on the $\mathrm{X}, \mathrm{Y}$ and $\mathrm{Z}$ axes, respectively.

Three certified radioactive standard solutions were used to obtain the experimental efficiencies in order to test the values calculated by the Monte Carlo method. The same standard solutions were used in a previous work to check the Monte Carlo code for a homogeneous aqueous source (Quintana and Montes, 2014). The first solution was the multi-nuclide standard 9ML01ELMH[05] by AREVA, traceable to COFRAC standard, containing ${ }^{60} \mathrm{Co},{ }^{57} \mathrm{Co},{ }^{109} \mathrm{Cd},{ }^{241} \mathrm{Am}$ and ${ }^{137} \mathrm{Cs}$. The second standard contained ${ }^{210} \mathrm{~Pb}$ and the third standard contained ${ }^{241} \mathrm{Am}$, both of them were provided by CIEMAT. Two spiked sources were prepared for the ceramic matrix by adding $1 \mathrm{~mL}$ of the ${ }^{210} \mathrm{~Pb}$ standard solution and $1 \mathrm{~mL}$ of the multi-nuclide standard, respectively, in a partially filled C21 box. The spiked ceramic was then dried in a heater, homogenized, and added to the box to a given volume. ${ }^{241} \mathrm{Am}$ spiked source was prepared using the same procedure with slag SL1 by adding $0.1 \mathrm{~mL}$ of ${ }^{241} \mathrm{Am}$ solution to a $\mathrm{C} 21$ box, and another ${ }^{241} \mathrm{Am}$ spiked source was prepared using the same procedure with the fly ashes FA1 by adding $0.1 \mathrm{~mL}$ of ${ }^{241} \mathrm{Am}$ solution to another $\mathrm{C} 21$ box. Finally, the same sources were spiked with $1 \mathrm{~mL}$ of ${ }^{210} \mathrm{~Pb}$ solution, following the same procedure as mentioned above.

The sources to be measured were placed on the HPGe detector window. Six measurements were taken for CUBE, one for each side of the sample. The spectrum of each of the spiked sources was acquired at different measurement times, ranging from $10,000 \mathrm{~s}$ to $36,000 \mathrm{~s}$. The

Table 1

Relevant source characteristics for the measurement of the different samples, where $h$ stands for the height the sample matrix reaches in the box used as a container and $\rho$, for the bulk density of the matrix in the box.

\begin{tabular}{lllllllll}
\hline $\begin{array}{l}\text { Sample } \\
\text { Geometry }\end{array}$ & CER & FA1 & FA2 & BOA & SL1 & SL2 & CE1 & CE2 \\
C11 & C21 & C21 & C21 & C21 & C21 \\
\hline$h(\mathrm{~mm})$ & 17.80 & 17.65 & 16.40 & 17.69 & 17.21 & 18.65 & 18.28 & 18.64 \\
$\rho\left(\mathrm{g} / \mathrm{cm}^{3}\right)$ & 1.571 & 1.056 & 1.361 & 1.061 & 1.327 & 1.323 & 1.426 & 1.467 \\
\hline
\end{tabular}




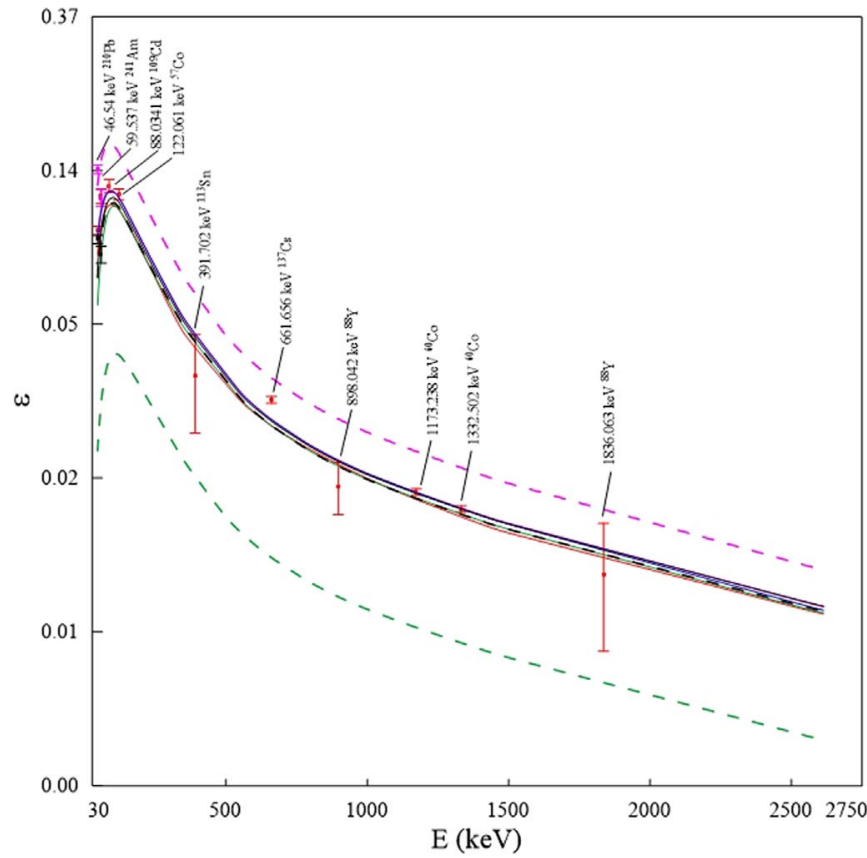

Fig. 3. Efficiency curves obtained with MC simulations for each set of matrix and geometry characteristics. Efficiency calibrations are represented for CER with a solid red line, for SL1 with a solid black line, for SL2 with a dashed black line, for FA1 with a solid magenta line, for FA2 with a dashed magenta line, for BOA with a solid blue line, for CE1 with a solid green line and for Cube with a dashed green line. Experimental points obtained from the spiked samples are depicted in the same colour as the curve, corresponding to the matrix used to make the calibration source. (For interpretation of the references to color in this figure legend, the reader is referred to the web version of this article.)

Table 2

MC coincidence summing corrections obtained for the main emissions from ${ }^{214} \mathrm{Bi}$ and ${ }^{208} \mathrm{Tl}$. Statistical uncertainties are given in parentheses.

\begin{tabular}{llllllll}
\hline $\mathrm{E}(\mathrm{keV})$ & $\mathrm{CSC}_{\mathrm{CER}}$ & $\mathrm{CSC}_{\mathrm{FA} 1}$ & $\mathrm{CSC}_{\mathrm{FA} 2}$ & $\mathrm{CSC}_{\mathrm{BOA}}$ & $\mathrm{CSC}_{\mathrm{SL} 1}$ & $\mathrm{CSC}_{\mathrm{SL} 2}$ & $\mathrm{CSC}_{\mathrm{CE} 1}$ \\
\hline 609.31 & $1.14(1)$ & $1.11(1)$ & $1.16(1)$ & $1.14(1)$ & $1.12(1)$ & $1.12(1)$ & $1.12(1)$ \\
1120.29 & $1.15(1)$ & $1.14(1)$ & $1.19(1)$ & $1.15(1)$ & $1.14(1)$ & $1.13(1)$ & $1.15(1)$ \\
583.19 & $1.19(1)$ & $1.18(1)$ & $1.22(1)$ & $1.18(1)$ & $1.17(1)$ & $1.15(1)$ & $1.17(1)$ \\
860.53 & $1.04(1)$ & $1.04(1)$ & $1.05(1)$ & $0.99(1)$ & $1.03(1)$ & $1.03(1)$ & $1.07(1)$ \\
\hline
\end{tabular}

measurement time for each sample source was $200,000 \mathrm{~s}$. The Galea program, as described above, was used for carrying out the $\gamma$ spectral analysis.

\section{Results}

Efficiency curves versus energy, suitable for each sample at its corresponding geometry of measurement, were obtained from the simulated values at different photon energies. The technique used to generate the curve to fit the MC data is described in (Janssen, 1990). All the curves obtained, one for each set of matrix and geometry characteristics are depicted in Fig. 3, together with the experimental values obtained from the spiked sources. One can observe as the curves corresponding to the same geometries but different matrixes differ mainly at low energies, which shows the need for a complete matrix characterization in the MC program. The experimental efficiency data from the spiked CER sources at medium and high energies, represented in Fig. 3, behave as the MC curve, although with higher uncertainties, while the experimental efficiency data at low energy from the spiked sources prepared with FA2, SL1 and CER matrixes show large deviations with respect to their corresponding curves. This is due to the difficulty in preparing homogeneous spiked samples for these matrices, making the MC method more useful for calculating the peak efficiencies. However, it is necessary to point out that the MC method was tested with homogeneous samples as previous step. The MC method is especially useful at low energies where important $\gamma$ emissions from natural radionuclides are located and efficiencies are more sensitive to matrix chemical composition.

Coincidence summing corrections were also calculated by using the MC method for the main emissions of ${ }^{214} \mathrm{Bi}$ and ${ }^{208} \mathrm{Tl}$. The values for the different samples are given in Table 2, where it can be observed that the corrections obtained were higher than $10 \%$ on average, with a maximum of $22 \%$. These corrections were used to calculate the activities of ${ }^{214} \mathrm{Bi}$ and ${ }^{228} \mathrm{Ra}$, assuming secular equilibrium with ${ }^{208} \mathrm{Tl} .{ }^{228} \mathrm{Ac}$ emissions were also taken into account in the ${ }^{228} \mathrm{Ra}$ activity calculation.

The uncertainty budget of the MC data obtained was estimated. Four main sources of uncertainty were considered: contribution to the different elements to the total chemical sample composition, matrix density, source to detector window distance and active crystal shape dimensions. The parameters involved were modified in the implementation of MC, taking into account the accuracy of their determination. Regarding the detector parameters, the accuracy was $0.5 \mathrm{~mm}$ for the source-to-detector distance, the resolution corresponded to the X-ray taken of the detector, and the accuracy of the crystal shape parameters was $0.43 \mathrm{~mm}$ for the upper half and $0.34 \mathrm{~mm}$ for the lower one. These values were taken from the work of Prieto and Quintana (2013). Regarding the sample matrix characteristics, the accuracy of the apparent density determination was $1.7 \%$, corresponding to the instruments used for its evaluation. The uncertainty associated with the determination of the chemical composition varied according to the sample and chemical element. For CER, SL1, SL2, FA1 and BOA, the uncertainty was $9.6 \%$ for $\mathrm{K}$ and $1.46 \%$ for $\mathrm{Si}$, and was, on average, $2.5 \%$ for the rest of elements. For FA2, CE1 and CE2, the uncertainty was $8 \%$ for $\mathrm{K}$ and $1 \%$ for $\mathrm{Si}$, being in average $3 \%$. The standard deviations in the MC results at the energies of interest are shown in Table 3. They are obtained propagating the quadratic deviations associated to each main source of uncertainty. These deviations were

Table 3

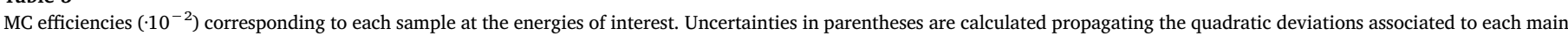
source of uncertainty considered in the MC calculation.

\begin{tabular}{|c|c|c|c|c|c|c|c|c|c|}
\hline Nuclide & $\mathrm{E}(\mathrm{keV})$ & $\varepsilon_{\mathrm{CER}}$ & $\varepsilon_{\mathrm{FA} 1}$ & $\varepsilon_{\mathrm{FA} 2}$ & $\varepsilon_{\mathrm{BOA}}$ & $\varepsilon_{\mathrm{SL1}}$ & $\varepsilon_{\mathrm{SL} 2}$ & $\varepsilon_{\mathrm{CE} 1}$ & $\varepsilon_{\mathrm{CE} 2}$ \\
\hline${ }^{238} \mathrm{U}$ & 63.30 & $9.65(55)$ & $10.76(58)$ & $15.05(32)$ & $10.57(56)$ & $9.56(55)$ & $9.17(56)$ & $8.36(57)$ & $8.00(56)$ \\
\hline${ }^{235} \mathrm{U}$ & 185.72 & $8.56(45)$ & $9.24(46)$ & $12.69(45)$ & $9.22(45)$ & $8.97(46)$ & $8.74(45)$ & $8.61(45)$ & $8.54(45)$ \\
\hline${ }^{230} \mathrm{Th}$ & 67.67 & $10.11(52)$ & $11.21(51)$ & $15.67(51)$ & $11.00(52)$ & $10.08(50)$ & $9.74(52)$ & $9.00(53)$ & $8.62(51)$ \\
\hline${ }^{226} \mathrm{Ra}$ & 186.21 & $8.53(46)$ & $9.22(46)$ & $12.62(47)$ & $9.20(46)$ & $8.92(46)$ & $8.67(46)$ & $8.60(48)$ & $8.49(46)$ \\
\hline${ }^{214} \mathrm{~Pb}$ & 351.93 & $4.70(26)$ & $4.98(28)$ & $6.80(26)$ & $4.98(26)$ & $4.91(26)$ & $4.76(26)$ & $4.75(26)$ & $4.66(26)$ \\
\hline${ }^{214} \mathrm{Bi}$ & 609.31 & $2.78(17)$ & $2.92(18)$ & $3.97(18)$ & $2.92(17)$ & $2.89(18)$ & $2.80(18)$ & $2.79(18)$ & $2.77(18)$ \\
\hline${ }^{210} \mathrm{~Pb}$ & 46.54 & $7.83(49)$ & $9.01(50)$ & $12.32(66)$ & $8.69(51)$ & $7.09(51)$ & $6.78(52)$ & $5.59(50)$ & $5.14(49)$ \\
\hline${ }^{228} \mathrm{Ra}$ & 911.20 & $1.98(10)$ & $2.06(10)$ & $2.80(11)$ & $2.03(10)$ & $2.04(11)$ & $1.96(10)$ & $1.97(11)$ & $1.94(11)$ \\
\hline${ }^{212} \mathrm{~Pb}$ & 238.63 & $7.02(38)$ & $7.46(37)$ & $10.17(39)$ & $7.47(38)$ & $7.31(38)$ & $7.08(38)$ & $7.00(38)$ & $6.96(38)$ \\
\hline${ }^{208} \mathrm{Tl}$ & 583.19 & 2.91(17) & $3.04(17)$ & $4.11(17)$ & $3.05(17)$ & $2.99(17)$ & $2.91(17)$ & 2.93(17) & $2.89(17)$ \\
\hline${ }^{40} \mathrm{~K}$ & 1460.83 & $1.31(8)$ & $1.37(16)$ & $1.84(8)$ & $1.37(8)$ & $1.38(8)$ & $1.31(8)$ & $1.33(8)$ & $1.32(9)$ \\
\hline
\end{tabular}



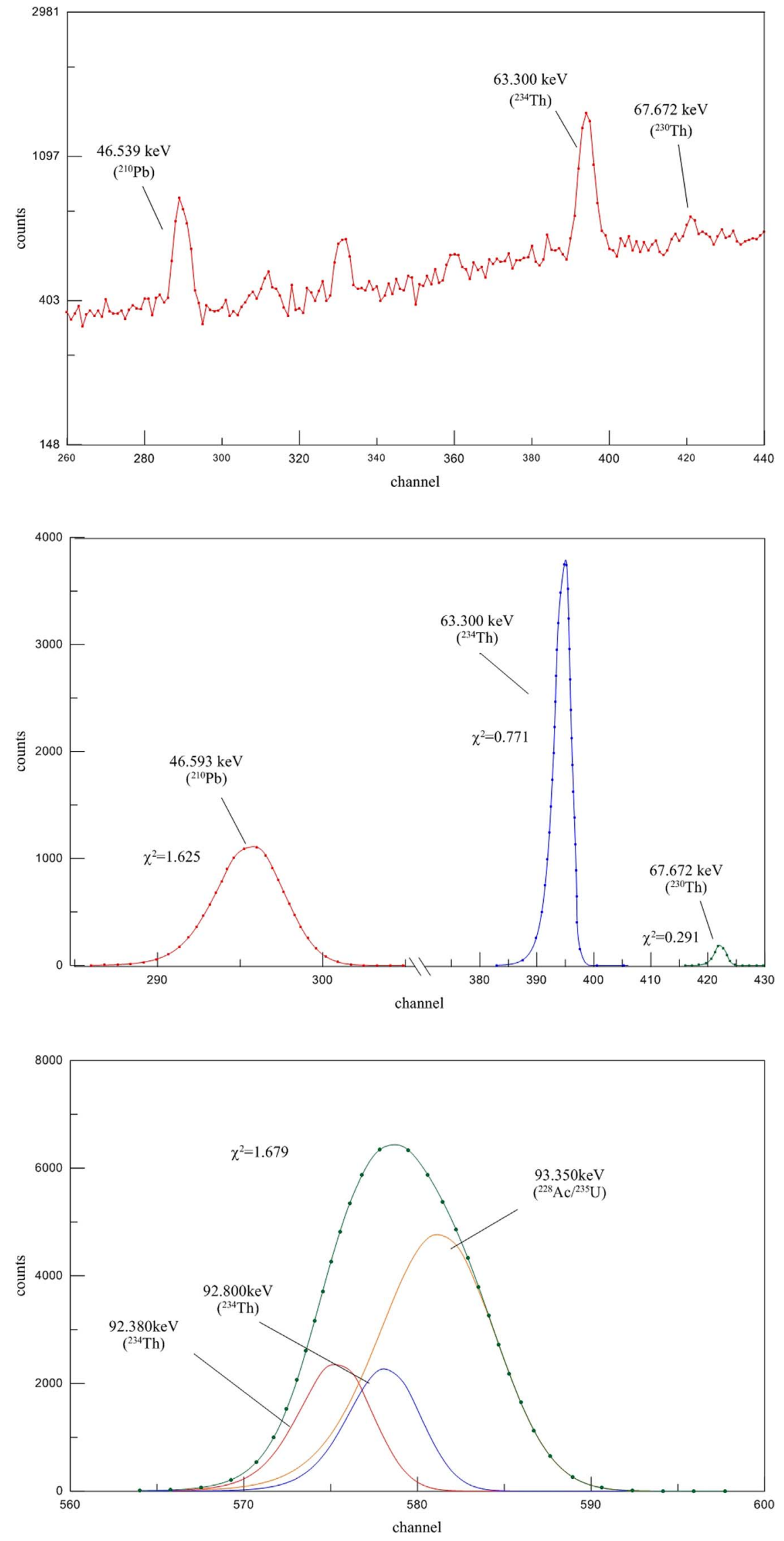

Fig. 4. Detail of the low-energy spectrum from source CE1, where the ${ }^{210} \mathrm{~Pb},{ }^{238} \mathrm{U}\left({ }^{234} \mathrm{Th}\right)$ and ${ }^{230} \mathrm{Th}$ emissions are shown.
Fig. 5. Fits of the ${ }^{210} \mathrm{~Pb},{ }^{238} \mathrm{U}\left({ }^{234} \mathrm{Th}\right),{ }^{230} \mathrm{Th} \gamma$-ray full-energy peaks in the CE1 spectrum.
Fig. 6. Fit of the multiplet shaped by the overlapping emissions at $92.38 \mathrm{keV}$ and $92.80 \mathrm{keV}$ from ${ }^{238} \mathrm{U}\left({ }^{234} \mathrm{Th}\right)$ and at $93.35 \mathrm{keV}$ from ${ }^{228} \mathrm{Ac}$ and ${ }^{235} \mathrm{U}$ in the BOA spectrum. 


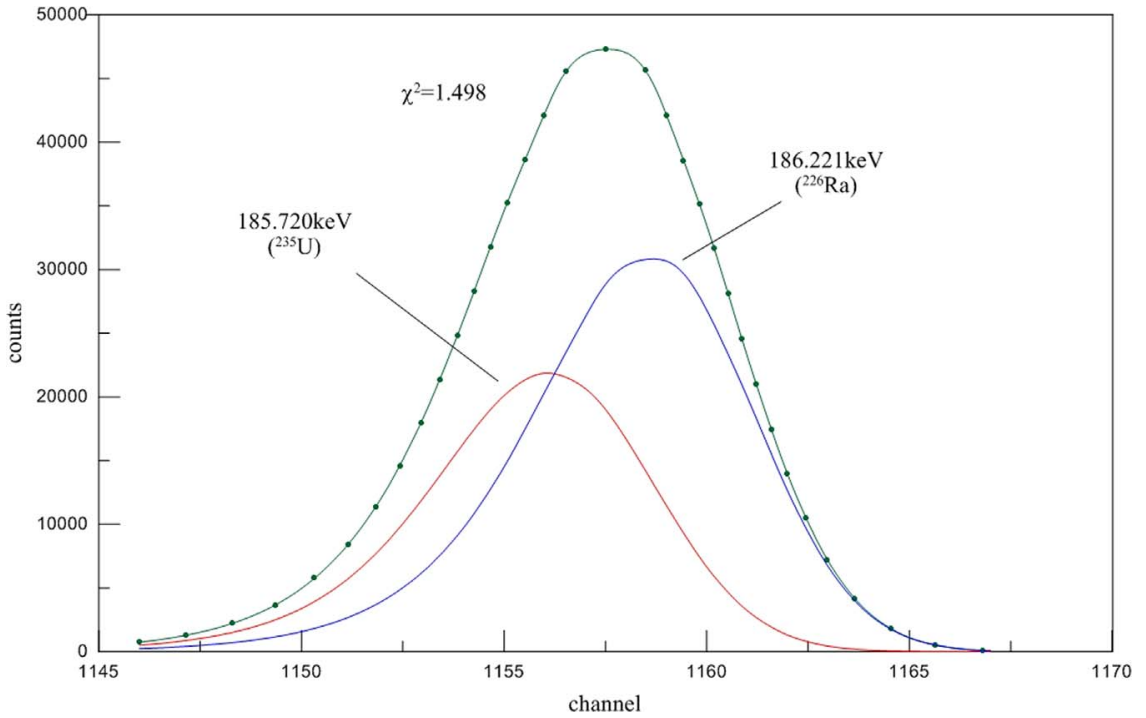

Fig. 7. Fit of the multiplet shaped by the overlapping emissions at $185.72 \mathrm{keV}$ from ${ }^{235} \mathrm{U}$ and $186.22 \mathrm{keV}$ from ${ }^{226} \mathrm{Ra}$ in the CER spectrum.

Table 4

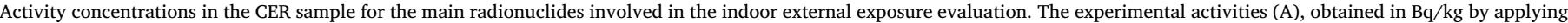
the full method described in this paper, are provided in the second row. Reference values $\left(\mathrm{A}_{\text {ref }}\right)$ provided in the third row are also in $\mathrm{Bq} / \mathrm{kg}$.

\begin{tabular}{|c|c|c|c|c|c|c|c|}
\hline Nuclide & ${ }^{238} \mathrm{U}$ & ${ }^{228} \mathrm{Ra}$ & ${ }^{226} \mathrm{Ra}$ & ${ }^{214} \mathrm{~Pb}$ & ${ }^{214} \mathrm{Bi}$ & ${ }^{210} \mathrm{~Pb}$ & ${ }^{40} \mathrm{~K}$ \\
\hline A & $124.2(76)$ & $65.9(35)$ & $127.0(80)$ & $123.2(69)$ & $126.1(78)$ & $119.6(76)$ & 999(13) \\
\hline$A_{\text {ref }}$ & $120(12)$ & $61.0(60)$ & $125(11)$ & $124(14)$ & $122(11)$ & $116(17)$ & $955(40)$ \\
\hline
\end{tabular}

Table 5

Activity concentrations in the CER sample for other relevant natural gamma emitters detected. As in Table 2, A stands for experimental activities in $\mathrm{Bq} / \mathrm{kg}$ and $\mathrm{A}_{\text {ref }}$ stands for the reference activities, also in $\mathrm{Bq} / \mathrm{kg}$.

\begin{tabular}{lllll}
\hline Nuclide & ${ }^{235} \mathrm{U}$ & ${ }^{230} \mathrm{Th}$ & ${ }^{212} \mathrm{~Pb}$ & ${ }^{208} \mathrm{Tl}$ \\
\hline $\mathrm{A}$ & $5.70(40)$ & $154(20)$ & $63.4(35)$ & $23.8(14)$ \\
$\mathrm{A}_{\mathrm{ref}}$ & - & - & $64.0(60)$ & $24.0(50)$
\end{tabular}

estimated varying in the MC implementation the parameter value corresponding to a source of uncertainty according to the accuracy of its determination.

Regarding the spectra analysis, the details of the low energy spectrum corresponding to CE1 is shown in Fig. 4. The peaks from ${ }^{210} \mathrm{~Pb}$, ${ }^{238} \mathrm{U}\left({ }^{234} \mathrm{Th}\right)$ and ${ }^{230} \mathrm{Th}$, once the continuous background is subtracted, and their corresponding fits are depicted in Fig. 5. One can observe as Galea succeeded in the analysis of these peaks in spite of the high background and the low counting statistics for ${ }^{230} \mathrm{Th}$. Two examples of the fits obtained from the overlapping full-energy peaks at $92-93 \mathrm{keV}$, with emissions of ${ }^{238} \mathrm{U}\left({ }^{234} \mathrm{Th}\right)$, and at $186 \mathrm{keV}$, with the main emissions of ${ }^{226} \mathrm{Ra}$ and ${ }^{235} \mathrm{U}$, are given in Figs. 6 and 7, respectively. Peak areas were initialized in the spectrum analysis by using the ${ }^{234} \mathrm{Th} 63.3 \mathrm{keV}$ peak area for the two multiplets. The initial areas were also corrected by efficiency and isotopic equilibrium, the latter only to calculate the initial ${ }^{235} \mathrm{U}$ peak area in the $186-\mathrm{keV}$ multiplet.

Results corresponding to the NORM4Building ceramic are given in Tables 4 and 5. Activity concentrations were obtained applying the MC efficiencies corresponding to matrix CER to the spectrum analysis carried out with Galea. Reference activities for this sample, taken from the NORM4Building intercomparison results (Xhixha et al., 2017), are also given in Tables 3 and 4 . These reference activities correspond to the mean value of the results provided by the participant laboratories. One can check the full agreement between experimental and reference values. The internal coherence among values corresponding to radionuclides belonging to the same natural decay series was preserved in the Galea analysis.

The radionuclide activity concentrations of the milled samples are given in Table 6. Slags SL1 and SL2 showed a higher concentration of Useries radionuclides, while bottom and fly ashes had higher concentrations of ${ }^{232} \mathrm{Th}$ daughters. However, the high activities from the Th-series radionuclides were not reflected in the cements manufactured with NORM mixes. Specifically, CE2 had FA2 as mix and CE1 was

Table 6

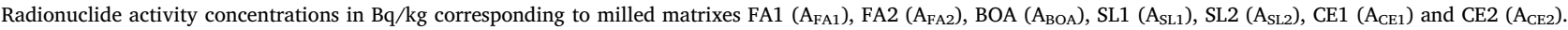

\begin{tabular}{|c|c|c|c|c|c|c|c|}
\hline Nuclide & $\mathrm{A}_{\mathrm{FA} 1}$ & $\mathrm{~A}_{\mathrm{FA} 2}$ & $\mathrm{~A}_{\mathrm{BOA}}$ & $\mathrm{A}_{\mathrm{SL} 1}$ & $\mathrm{~A}_{\mathrm{SL} 2}$ & $\mathrm{~A}_{\mathrm{CE} 1}$ & $\mathrm{~A}_{\mathrm{CE} 2}$ \\
\hline${ }^{238} \mathrm{U}$ & $86.4(56)$ & $78.0(36)$ & $66.0(41)$ & $126.6(78)$ & $139.3(90)$ & $20.2(16)$ & $29.2(23)$ \\
\hline${ }^{235} \mathrm{U}$ & $3.47(22)$ & $3.84(47)$ & $2.88(38)$ & $6.44(43)$ & $6.41(40)$ & $0.788(61)$ & $1.39(11)$ \\
\hline${ }^{230} \mathrm{Th}$ & $64.1(34)$ & $66(13)$ & $71(12)$ & $159(21)$ & $143(15)$ & $13.0(36)$ & $26.6(51)$ \\
\hline${ }^{226} \mathrm{Ra}$ & $80(10)$ & $74.0(71)$ & $73.1(65)$ & $127.0(78)$ & $134.4(80)$ & 23.3(15) & $29.8(20)$ \\
\hline${ }^{214} \mathrm{~Pb}$ & $74.9(42)$ & $77.3(30)$ & $66.0(35)$ & $128.6(80)$ & $132.6(81)$ & $20.2(14)$ & $28.7(16)$ \\
\hline${ }^{214} \mathrm{Bi}$ & $75.7(47)$ & $79.7(36)$ & $69.6(41)$ & $130.7(82)$ & $142.2(92)$ & 20.3(13) & $29.0(19)$ \\
\hline${ }^{210} \mathrm{~Pb}$ & $101.6(60)$ & $84.1(50)$ & $28.8(21)$ & $3.24(50)$ & $2.05(45)$ & $18.7(12)$ & $29.0(29)$ \\
\hline${ }^{228} \mathrm{Ra}$ & $104.3(53)$ & $49.7(25)$ & $96.5(53)$ & $45.8(26)$ & $41.7(24)$ & $20.6(12)$ & $9.58(61)$ \\
\hline${ }^{212} \mathrm{~Pb}$ & $101.6(96)$ & $51.9(27)$ & $94.3(49)$ & 44.1(23) & $40.8(22)$ & $19.61(11)$ & $10.12(62)$ \\
\hline${ }^{208} \mathrm{Tl}$ & $35.7(20)$ & $19.37(88)$ & $35.8(20)$ & $16.46(95)$ & $15.26(91)$ & $7.19(84)$ & $3.78(23)$ \\
\hline${ }^{40} \mathrm{~K}$ & $1030(14)$ & $493(23)$ & $974(58)$ & $135.3(83)$ & $119.9(77)$ & $235(14)$ & $170(12)$ \\
\hline
\end{tabular}


Table 7

Radionuclide activity concentrations in $\mathrm{Bq} / \mathrm{kg}$ for the cement cube (CUBE) measured on each side. A refers to the average activity.

\begin{tabular}{|c|c|c|c|c|c|c|c|}
\hline Nuclide & $\mathrm{A}_{1}$ & $\mathrm{~A}_{2}$ & $\mathrm{~A}_{3}$ & $\mathrm{~A}_{4}$ & $\mathrm{~A}_{5}$ & $\mathrm{~A}_{6}$ & A \\
\hline${ }^{238} \mathrm{U}$ & 47.2 (17) & 45.1 (19) & 47.1 (17) & 49.5 (15) & $49.5(16)$ & 49.7 (15) & $48.27(67)$ \\
\hline${ }^{235} \mathrm{U}$ & 2.09 (18) & $2.11(14)$ & $2.13(18)$ & $2.20(23)$ & $2.28(26)$ & $2.2(11)$ & $2.139(82)$ \\
\hline${ }^{230} \mathrm{Th}$ & 52.9 (97) & $49.8(86)$ & 58.7 (93) & 57.9 (89) & $63.0(82)$ & $53(12)$ & $56.3(38)$ \\
\hline${ }^{226} \mathrm{Ra}$ & 44.1 (27) & 44.4 (19) & 46.2 (27) & 42.9 (35) & 42.4 (39) & $42.4(16)$ & $43.64(96)$ \\
\hline${ }^{214} \mathrm{~Pb}$ & $41.81(34)$ & $41.13(31)$ & $41.85(32)$ & $42.44(26)$ & $41.31(24)$ & $41.54(31)$ & 41.69 (12) \\
\hline${ }^{214} \mathrm{Bi}$ & $44.30(55)$ & $44.98(55)$ & 44.85 (55) & $44.02(54)$ & 44.07 (48) & $43.76(52)$ & $44.31(22)$ \\
\hline${ }^{210} \mathrm{~Pb}$ & $42.5(12)$ & 41.1(17) & $42.8(12)$ & $40.9(12)$ & $41.3(10)$ & $41.0(11)$ & $41.58(50)$ \\
\hline${ }^{232} \mathrm{Th}$ & 25 (18) & 21 (19) & 33 (19) & $20(16)$ & $20(12)$ & 21 (15) & $24.5(65)$ \\
\hline${ }^{228} \mathrm{Ra}$ & $23.17(61)$ & $23.48(61)$ & $22.84(60)$ & $23.17(60)$ & $23.04(58)$ & $23.22(60)$ & $23.15(24)$ \\
\hline${ }^{212} \mathrm{~Pb}$ & $21.50(30)$ & $21.99(30)$ & $21.61(30)$ & $21.77(30)$ & $21.88(28)$ & $21.81(30)$ & 21.76 (12) \\
\hline${ }^{208} \mathrm{Tl}$ & 8.89 (16) & $9.51(16)$ & $9.26(16)$ & $9.28(16)$ & 9.17 (14) & 9.14 (15) & $9.205(63)$ \\
\hline${ }^{40} \mathrm{~K}$ & 164.3 (29) & $168.6(28)$ & $168.0(33)$ & 168.6 (39) & $161.8(30)$ & $171.6(28)$ & 167.1 (12) \\
\hline
\end{tabular}

produced without additions of NORM wastes, but ${ }^{228} \mathrm{Ra}$ and ${ }^{212} \mathrm{~Pb}$ activities are higher in CE1 than in CE2. Regarding the other radionuclides, CE2 show significantly higher concentrations than CE1 for ${ }^{210} \mathrm{~Pb}$ and ${ }^{230} \mathrm{Th}$, radionuclides that are not considered in the ACI. Internal coherence among values corresponding to radionuclides, belonging to the same natural decay series, was still preserved in all the measurements.

The radionuclide activity concentrations measured for CUBE, the compacted cement sample, are given in Table 7. It is noteworthy that ${ }^{232} \mathrm{Th}$ was determined from its weak emission at $63.3 \mathrm{keV}$, which shaped a multiplet together with the 63.7 emission from ${ }^{238} \mathrm{U}\left({ }^{234} \mathrm{Th}\right)$. Although ${ }^{232} \mathrm{Th}$ activity uncertainties were high, it is needed to take ${ }^{232} \mathrm{Th} \gamma$-ray emission into account for the correct determination of ${ }^{238} \mathrm{U}$ ( $\left.{ }^{234} \mathrm{Th}\right)$.

\section{Summary}

The main natural radionuclides from the $\mathrm{U}$ and Th decay series were determined by gamma spectrometry with a HPGe detector in a wide variety of building materials from milled samples, such as ceramics, fly ashes, bottom ashes, slags, cement, and a compacted cement sample. All the determinations, independently of the measurement conditions, were made with the same procedure: Monte Carlo simulations for efficiency calculations and Galea for spectrum analysis. The results indicate that the full procedure is reliable and reduces the amount of time needed to obtain experimental efficiency calibrations. Additionally, the gamma spectrum analyser tool, Galea, is capable of successfully analysing even the lowest gamma lines, detecting the activities of weak emitters such as ${ }^{232} \mathrm{Th}$ and ${ }^{230} \mathrm{Th}$. Hence, this procedure facilitates the complete radiological characterization for NORM building materials, and has demonstrated its usefulness as a way to measure a wide variety of matrices and geometries.

\section{References}

Agostinelli, S., Allison, J., Amako, K., Apostolakis, J., Araujo, H., et al., 2003. Geant4—a simulation toolkit. Nucl. Instrum. Methods A 506, 250-303.

Council Directive 2013/59/Euratom, 2013. Laying Down Basic Safety Standards For Protection Against The Dangers Arising From Exposure To Ionising Radiation, and Repealing Directives 89/618/Euratom, 90/641/Euratom, 96/29/Euratom, 97/43/ Euratom and 2003/122/Euratom. L13, Vol. 57, ISSN 1977-0677. 〈http://doi.org/10. 3000/19770677.L_2014.013.eng .

Currie, L.A., 1968. Limits for qualitative detection and quantitative determination. Anal. Chem. 40, 586-593.

Hernández-Prieto, A., Quintana, B., Martín, S., Domingo-Pardo, C., 2016. Study of accuracy in the position determination with SALSA, a g-scanning system for the characterization of segmented HPGe detectors. Nucl. Instrum. Methods A 823, 98-106.

Janssen, H., 1990. Spline techniques for fitting efficiency curves in $\gamma$-ray spectrometry. Nucl. Instrum. Methods A 286, 398-402.

LNHB, 2017. Nucléide-Lara, Library for Gamma and Alpha Emissions. 〈http://www. nucleide.org/Laraweb/>.

Prieto, A.H., Quintana, B., 2013. Characterization of a high spatial resolution gamma camera for scanning HPGe segmented detectors. IEEE Trans. Nucl. Sci. 60, 4719-4726.

Quintana, B., Fernández, F., 1998. Gamma-ray spectral analysis with the COSPAJ continuum fitting routine. Appl. Radiat. Isot. 49, 1235-1240.

Quintana, B., Montes, C., 2014. Summing-coincidence corrections with Geant4 in routine measurements by $\gamma$ spectrometry of environmental samples. Appl. Radiat. Isot. 87, 390-393.

Santamaría, R., Quintana, B., Lorenzo, F., Pedrosa, M.C., 2017. A genetic algorithm to analyze $\gamma$-ray spectra from HPGe detectors. Nucl. Instrum. Methods A.

Siegert, H., Janssen, H., 1990. Precise determination of gamma-ray peak areas. Nucl. Instrum. Methods A 286, 415-420.

Xhixha, G., Trinidad, J.A., Gascó, C., Mantovani, F., 2017. First intercomparison among laboratories involved in COST Action-TU1301 "NORM4Building": determination of natural radionuclides in ceramics. J. Environ. Radioact. 168, 4-9. 